\title{
اختيار النائب البرلماني وأثره على جودة التشريعات
}

\section{قمر الدين عبد الرحمن السماني الشيخ برير}

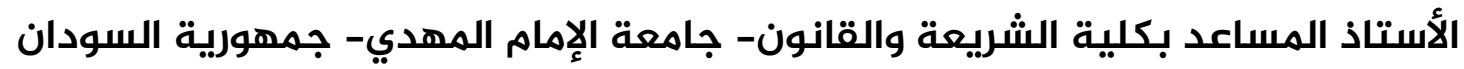
الأستاذ المساعد بكلية العلوم الإدارية-قسم الأنظمة-جامعة نجرانه الماهمة المملكة العربية السعودية gamerdorean@hotmail.com 
www.refaad.com
المجلة الدولية للدراسات القانونية والفقهية المقارنة

International Journal of Legal and Comparative Jurisprudence Studies (LCJS)

Journal Homepage: https://www.refaad.com/views/LCJS/Home.aspx

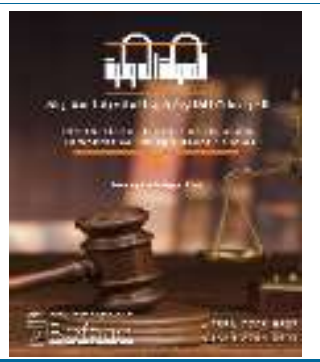

ISSN: 2708-6607(Online) 2708-6593(Print)

\title{
اختيار النائب البرلماني و أثره على جودة التشريعات
}

\author{
قمر الدين عبد الرحمن السماني الشيخ برير

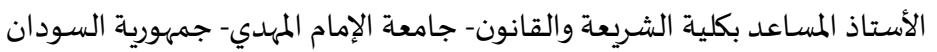

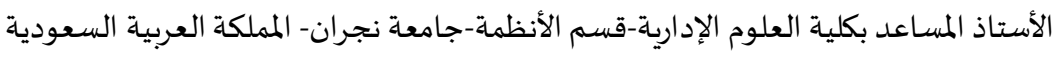 \\ gamerdorean@hotmail.com
}

DOI: https://doi.org/10.31559/LCJS2021.2.1.5 2021/5/3 2021/2/4 مراجعة البحث: 2021/4/14 قبول البحثلام البحث:

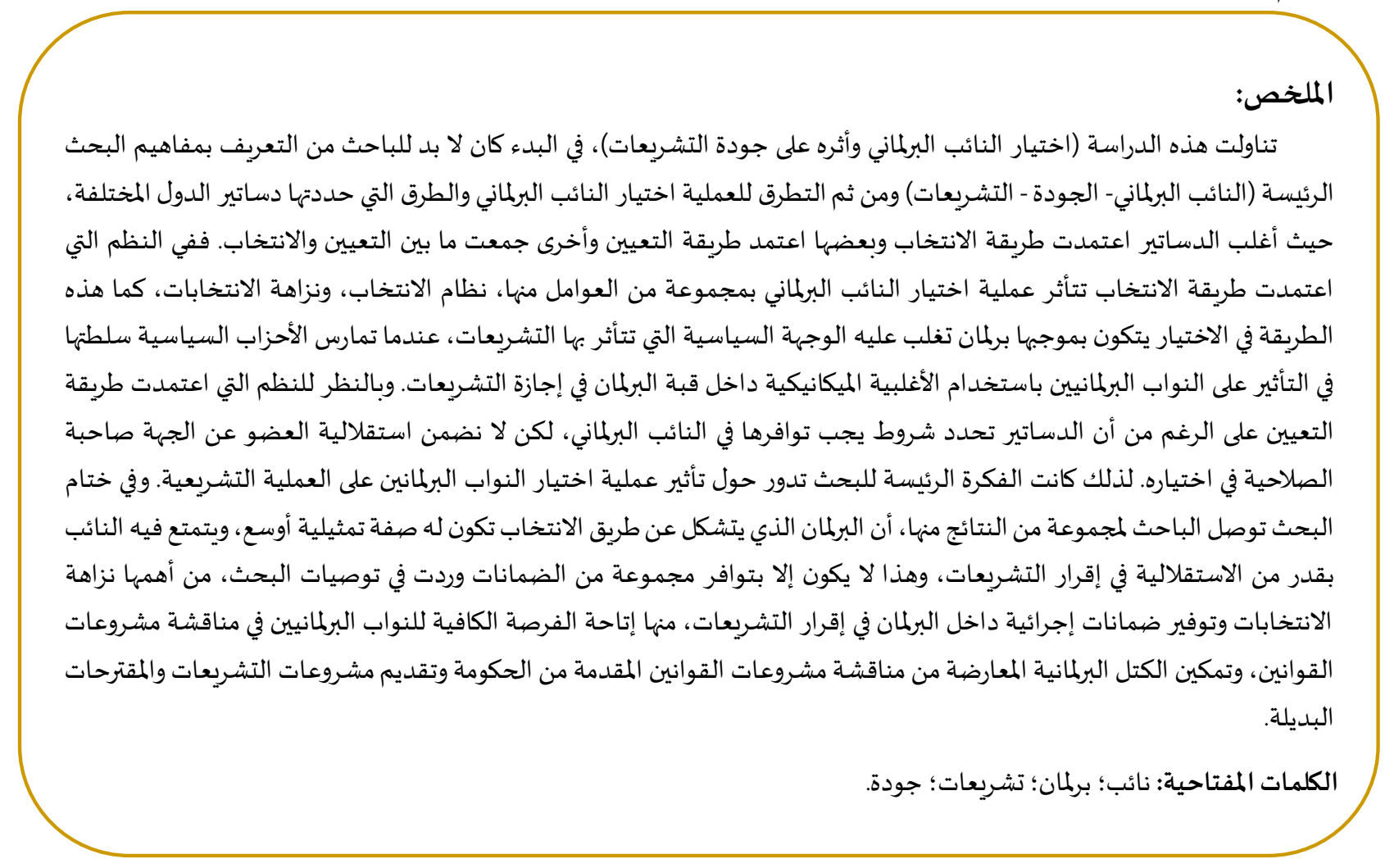

المقلدمة:

تشكيل البرلمان يختلف من دولة إلى أخرى بحسب طبيعة الدولة ونظامها السياسي ونظام الحكم فيها، لذلك اعتمدت دساتير الدول طرق مختلفة

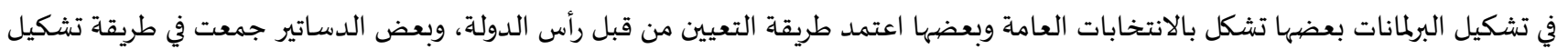

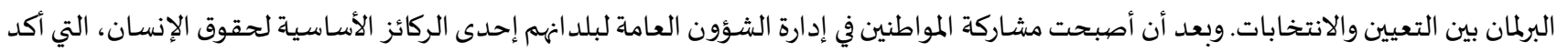

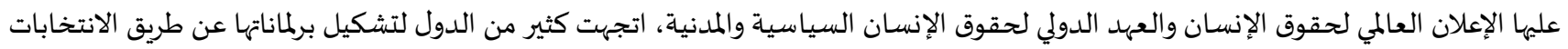

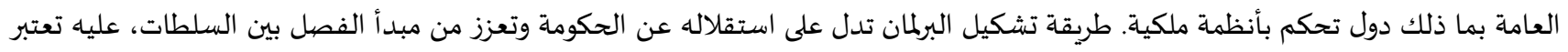

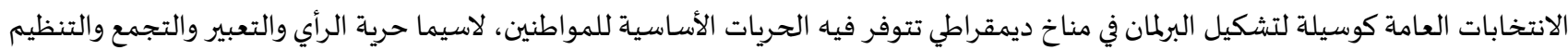


والتعددية السياسية، من أفضل الطرق التي يتشكل بها برلمان أكثر تمثيلاً للشعب. ويتأثر أداء البرلمان كهيئة جماعية ونواب بطريقة تشكيله، سواء كان

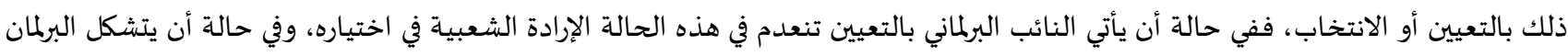

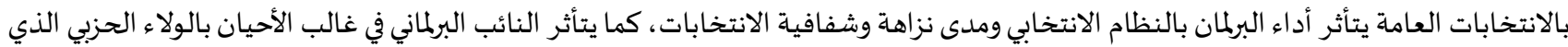
يجعله ينضوي تحت كتلة سياسية داخل البرلمان.

مشكلة الدراسـة:

تكمن مشكلة الدراسة في عدم وضيع معايير وشروط دقيقة لاختيار النائب البرلماني، وبعد الاطلاع على غالب الدساتير نجد أهنا اعتمدت شروط عامة

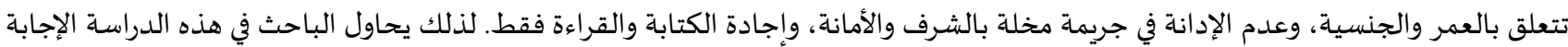
على مجموعة من الأسئلة تدور حول مشكلة البحث. 1. هل يتأثر أداء النائب البرلماني بطريقة اختئه تدول مئكاره سواء كان بالتعيين أو الانتخاب؟

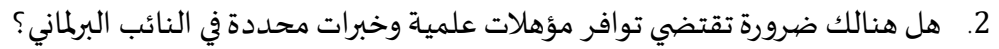

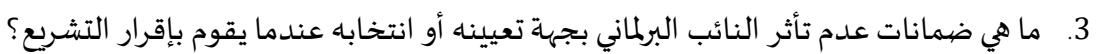

أهمية الدراسـة:

ضمان جوددة التشريعات في الدولة يعتبر من أهم سمات النظام القانوني للدولة الحديثة وركن أساسي من أركان الدولة القانونية، وهو أيضياً من

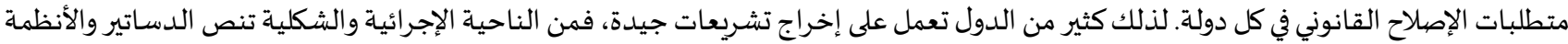

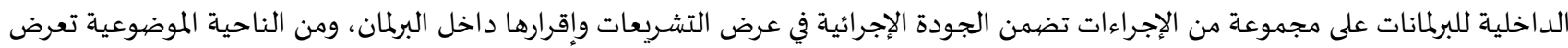
مشروعات القوانين على الأشخاص المعنيين بالقانون وتتم استشارات فنية ومجتمعية واسعة، ومن ناحية الصياغة تنشأ هيئات مختصاية بالصياغـة التشريعية. وعلى الرغم من ذلك تتأثر التشريعات سلباً بضعف المشرع (النائب البرلماني) عندما تنقصها الخبرة والكفاءة اللازمة للقيام بمهمته في إقرار التشريع، أو قد ينقصاه استقلال القرار في التصويت بسبب عدم استقلاله عن صاحب السلطة في تعينه أو الولاء للحزب السياسي، هذا ما يضعف أداء

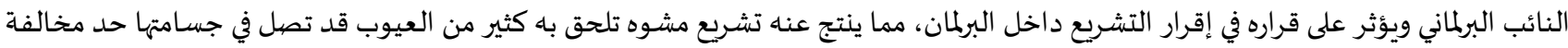
الدستور والمبادئ الأساسية، أو المساس بالحقوق والحريات العامة، أو على أقل تقدير عدم الدقة في اللغة والوضوح أو الانسجام التشريعي مع القوانين السارية في الدولة.

أهداف الدراسة:

تهدف هذه الدراسة إلى تحقيق الآتي: 1. وضع معايير دقيقة لاختيار النواب البرلمانيين.

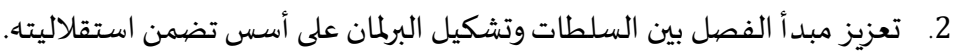

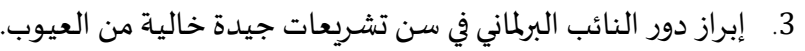

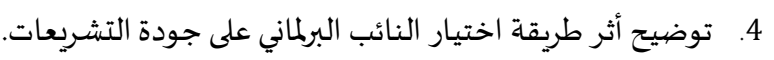

\section{المبحث الأول: مفاهيم المصطلحات الأسـاسية في البحث}

يتناول هذا المبحث دراسة المفاهيم الأسـاسية للبحث (النائب البرلماني- التشريع -الجودة) بالتعريف بها في اللغة وبيان مدلولها في الاصطلاح الفقهي والقانوني. المطلب الأول: التعريف اللغوي لمصطلحات البحث تعريف النائب البربماني: كلمة (النائب) تأتي من النيابة ومصيدرها الفعل (ناب) وتعني في اللغة العربية: (ناب) الشيء نوباً: قرب إلى الشيء ورجع إليه وأعتاده،

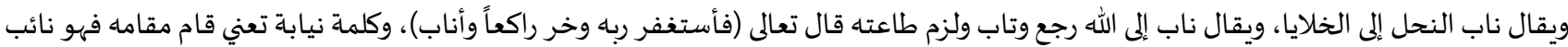

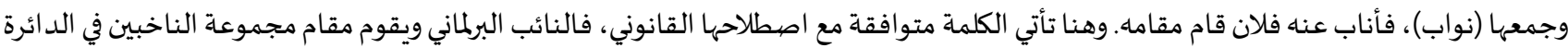

الجغرافية التي يمثلها في برابلمان الدولة.

1 أنيس، ابراهيم- منتصر، عبد الحليم- الصوالجي، عطية- أحمد، محمد خلف الله، المعجم الوسيط، ط/4، مجمع اللغة العربية ،مكتبة الشروق، 2004،ط4.ص 961. 
أما كلمة برلمان أصلها فرنسية (parler) وتعني الحوار والنقاش وهي كلمة معربة، ويطلق لفظ (برلمان) على الهيئة التشريعية في الدولة التي تتكون

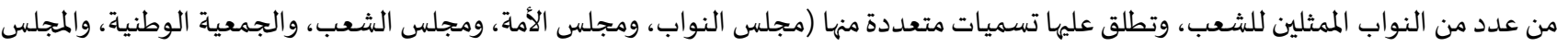

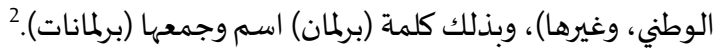

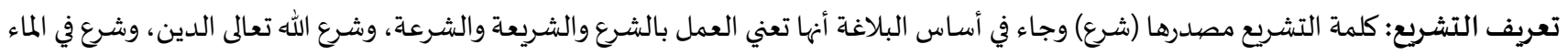

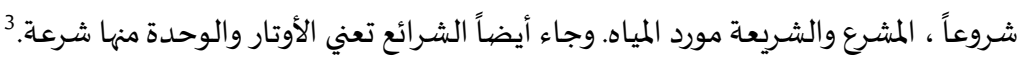

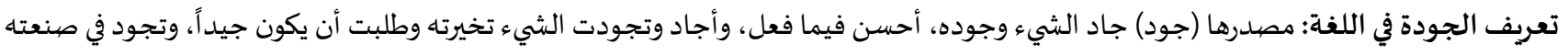

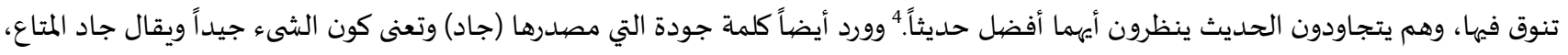

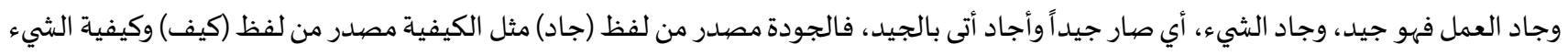
تعني حالته وصيفته.5 وجداد

$$
\text { المطلب الثاني: التعريف الاصطلاحي لمفردات البحث }
$$

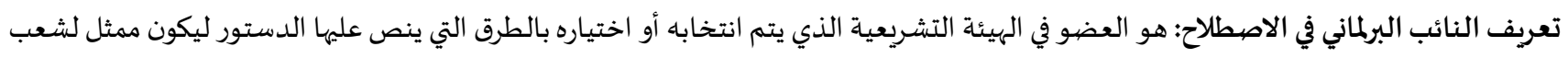
دائرة جغرافية محددة، ونيابة عنهم يقوم بمهام دستورية يحددها الدستور ونظام الهيئة التشريعية (تشريعية، ورقابية، وسياسية) ولفترة انتخابية محددة، ويتمتع بحصيانة (برلمانية) تحمياه من المساءلة.

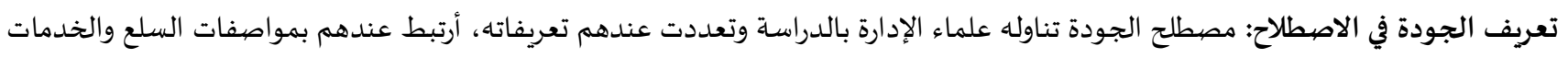

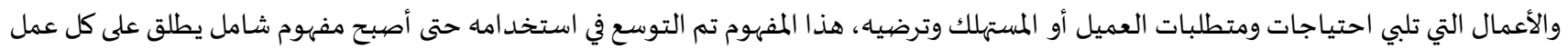

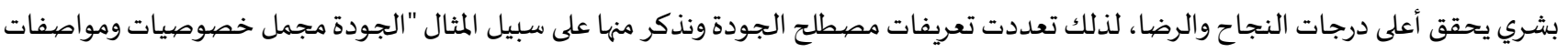

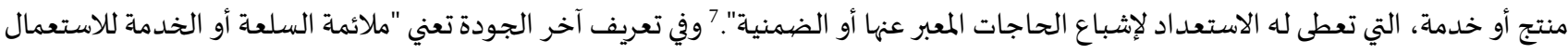

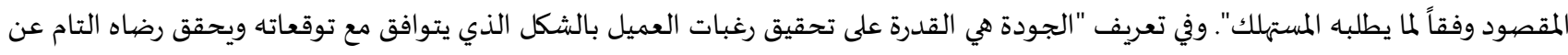

السلعة أو الخدمة التي تقدم له".

مما تقدم يمكن تحديد مفهوم جودة التشريعات، بأن يصدر التشريع من السلطة المختصة وفق المعايير التي تضبط جودة التشريعات من حيث

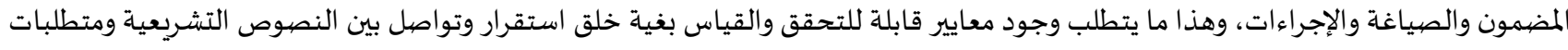

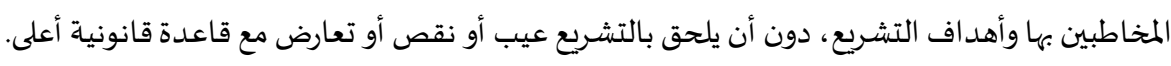

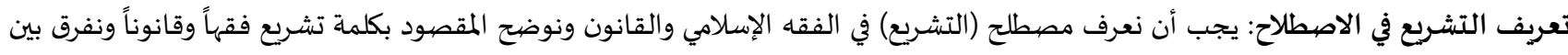

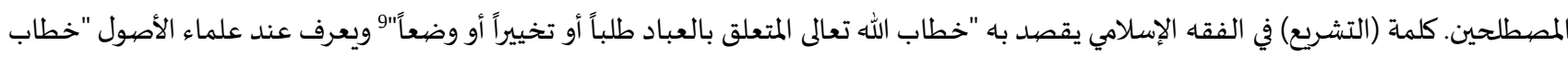

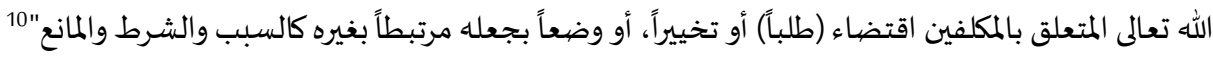

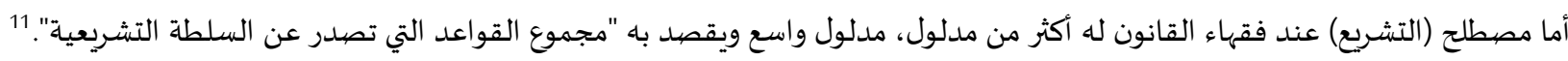

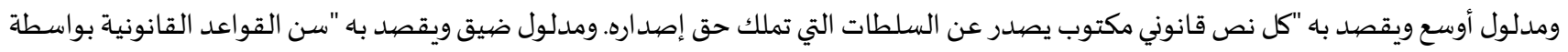

السلطة المختصية"12

ولذلك كان واجب أن نفرق بين استخدام مصطلح (التشريع) عند فقهاء الشريعة والقانون، عند فقهاء الشريعة يعتبر الخطاب الموجه من الله تعالى للعباد، وهذا مفهوم واسع يشمل كل ما يصدر من الشارع من نصوص. وعند الأصوليين يضيق المفهوم حيث يقتصر على الخطاب الموجاه للمكلفين الذي

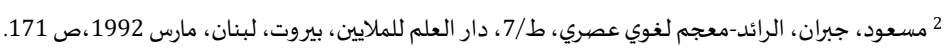

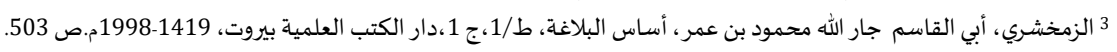
ألمرجع السابق ص 154.

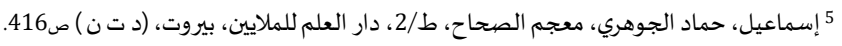

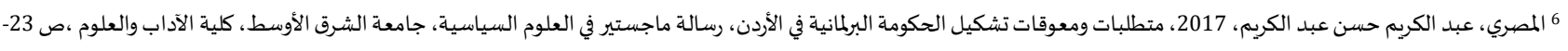


يستنبط منه الحكم الشرعي. أما استخدام مصطلح التشريع في القانون يطلق على النصوص التي تضعها السلطة التشريعية، وبهذا المعنى يعد التشريع مصدراً رسمياً وأصلياً للقاعدة القانونية المكتوبة.

\section{المبحث الثاني: طرق اختيار النائب البرلماني وشروطه}

بعد الاطلاع على مجموعة من الدساتير لمجموعة من الدول المختلفة في أنظمتها الحاكمة (الملكية والجمهورية) والمختلفة في مرجعتيها الفكرية

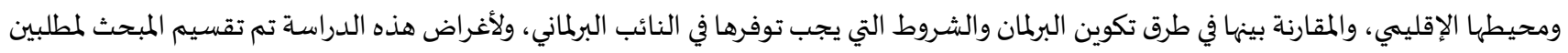
الأول تناول طرق اختيار النائب والثاني تناول شروط النائب البائب البرلماني.

$$
\text { المطلب الأول: طرق اختيار النائب البرلماني }
$$

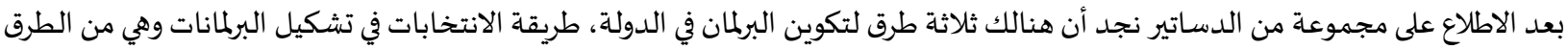

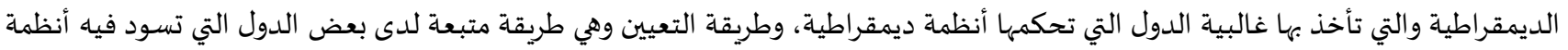

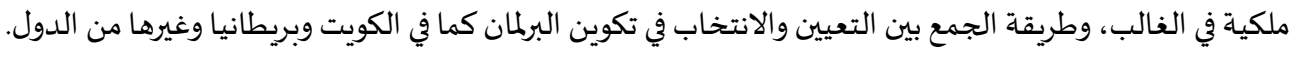

الفرع الأول: الانتخابات (Elections) تعد الانتخابات بمثابة الوسيلة الأساسية التي تؤهل الناس للمشاركة في إدارة الشؤون العامة لبلدانهم، كما يعتبر الانتخاب حقاً أساسياً من حقوق الأنا

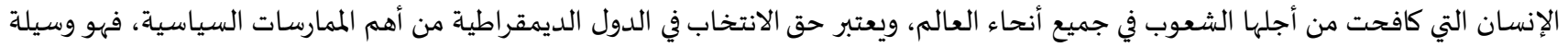

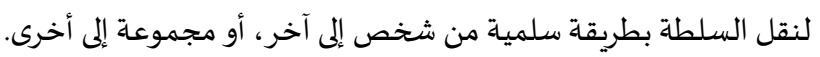

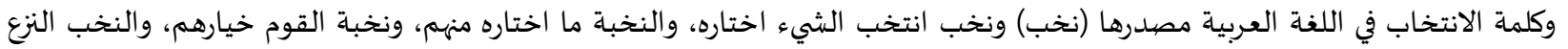

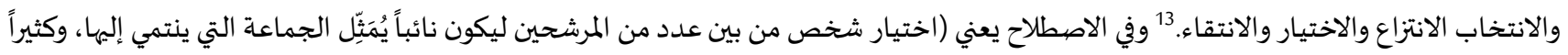
ما يطلق على الانتخاب اسم (اقتراع).

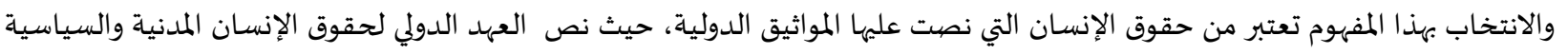

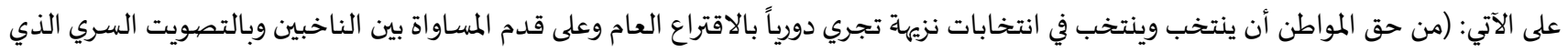

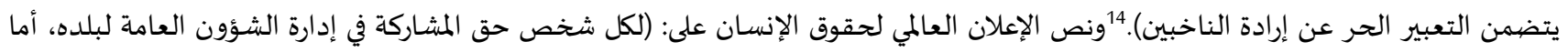

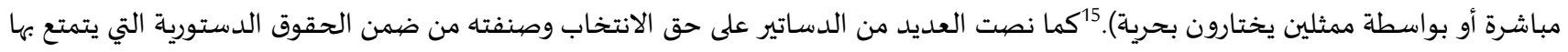

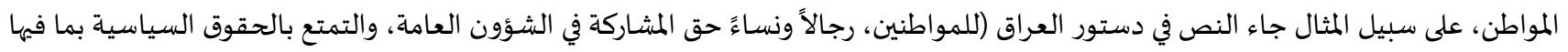
حق التصويت والانتخاب والترشيح).

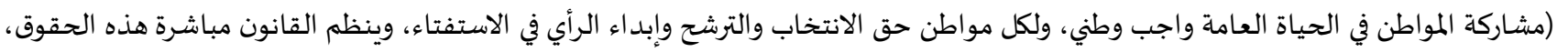

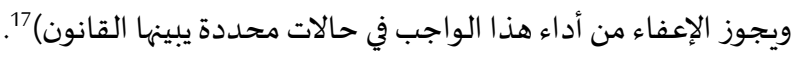

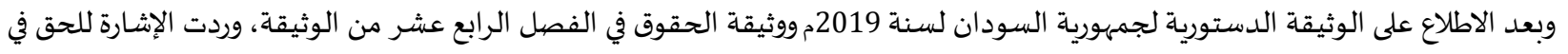

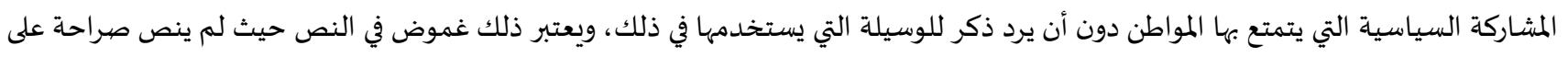

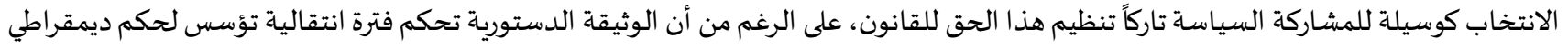

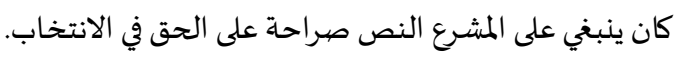

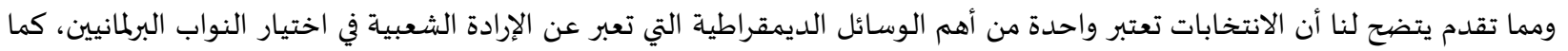

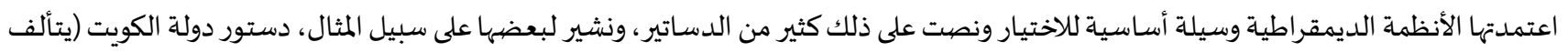

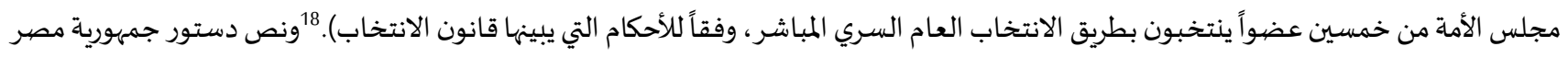

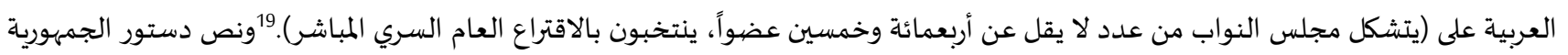

13 الأنصاري، ابن منظور جمال الدين محمد بن مكرم، لسان العرب، الدار المصرية للتأليف والترجمة،جح، ص649.

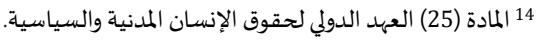
15 المادة 21 من المادة (25 العهلان العالمي لحقوق الإنسان المانسان.

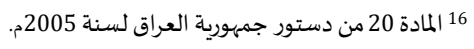

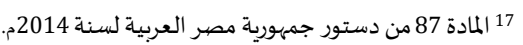
18 المادة 80 من دستور دولة الكويت 187 من دستور جمرية 1992. 19 المادة 102 من دستور جمنهورية مصر العربية لسنة 2014م. 


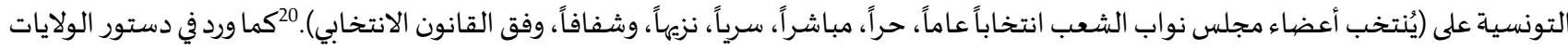

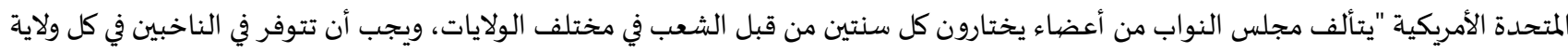

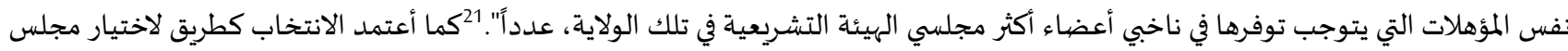
العموم البريطاني (House of Commons of the United Kingdom).

الفرع الثاني: التعيين (appointment)

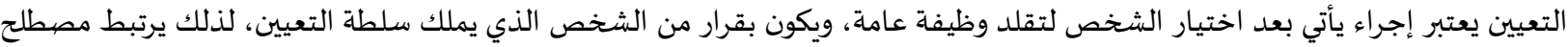

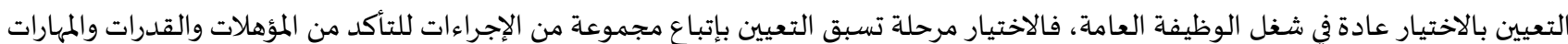

التي يمتلكها المتقدم لشغل الوظيفة العامة وبناء على ذلك يتم اختيار الشخص الأكفأ والأجدر للقيام بمهام الوظئيفة.

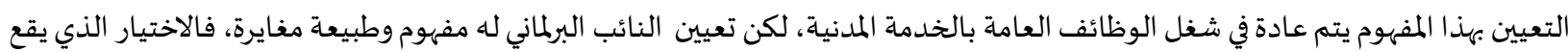

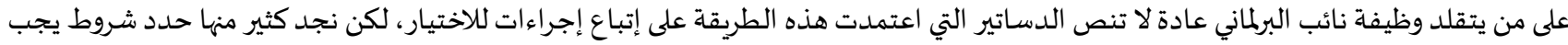

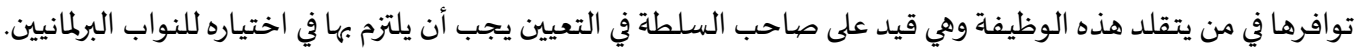

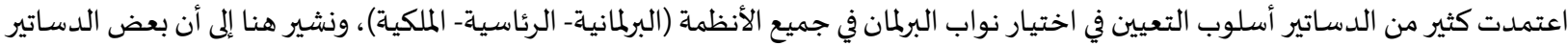

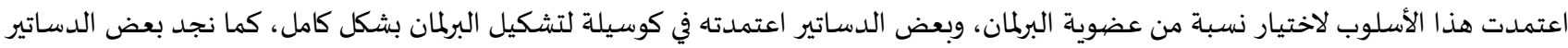

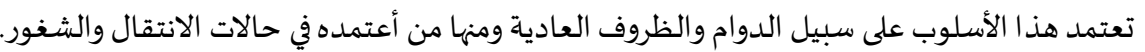

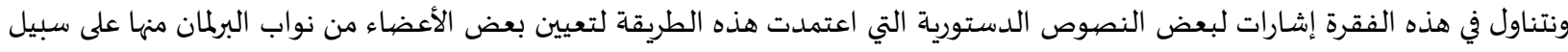

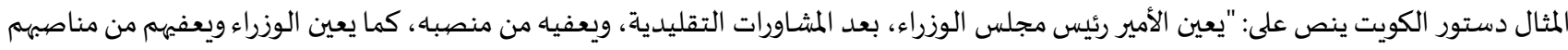

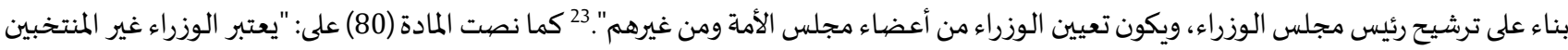

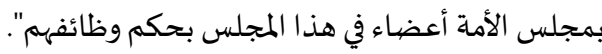
ينص دستور الولايات المتحدة الأمريكية: "في حالة شغور مقعد أو أكثر بسبب الاستقالة أو سواها، خلال عطلة السلطة التشريعية لولاية ما، جاز

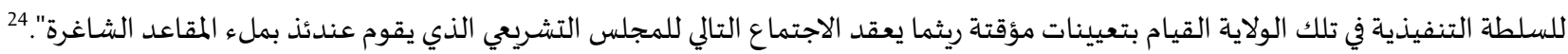

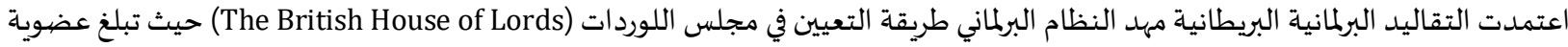

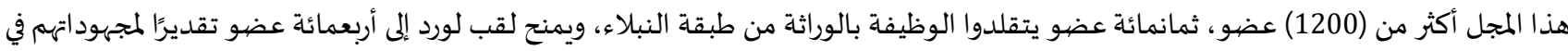

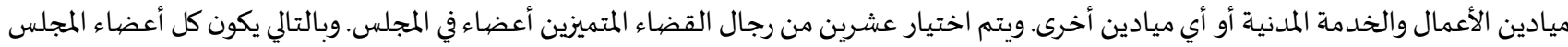

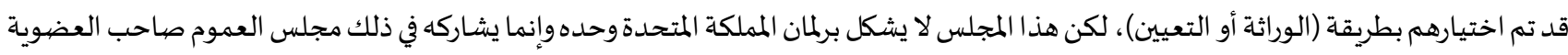
المنتخبة بالكامل.

ومن الدساتير والأنظمة التي اعتمدت التعيين كطريقة لاختيار كامل أعضاء المجلس والبرلمان نظام مجلس الشورى في المملكة العربية السعودية،

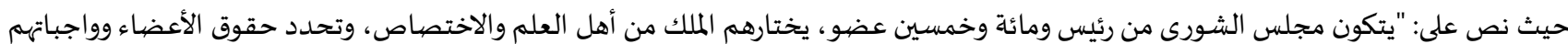

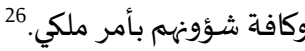

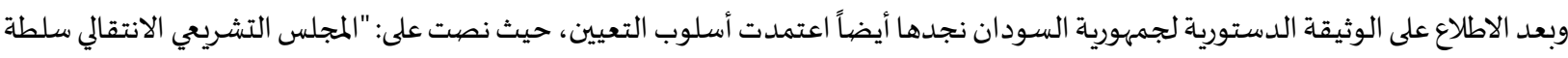

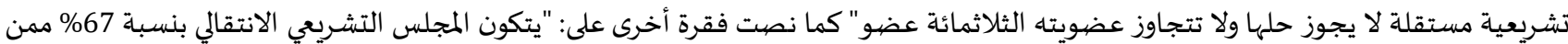
تختارهم قوى إعلان الحرية والتغيير ، ونسبة 33\% للقوى الأخرى غير الموقعة على إعلان الحرية والتغيير والتي يتم تسميتها وتحديد نسبة مشاريان التهاركة كل منها

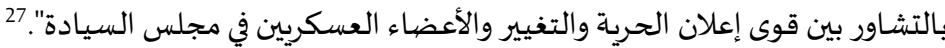

20 المادة 55 من الدستور الجمهورية التونسية لسنة 2014م.

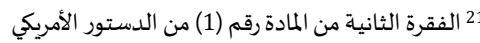

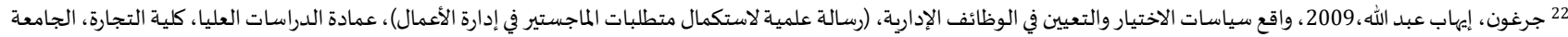

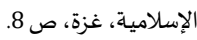

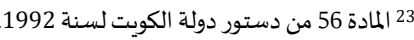

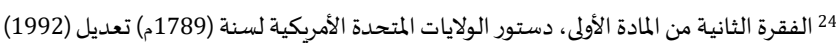

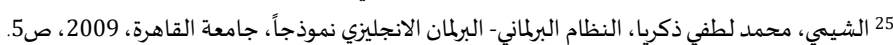
26 المادة الثالثة من نظام مجلس الشورى لسنة النئة 1412. 27 المادة 24 من المثيقة الدائة من نمستوربة للفترة الانتقالية- جمهورية السودان لسنة 1412 2019م. 
المطلب الثاني: شروط النائب البرلماني

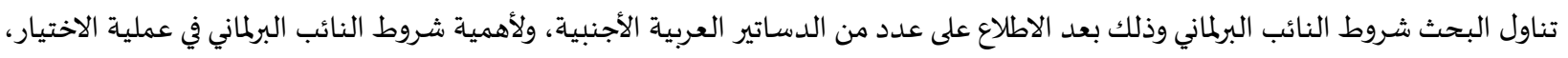

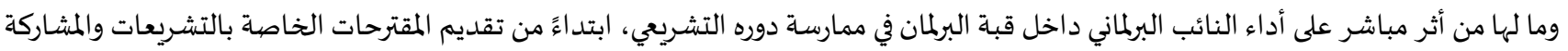

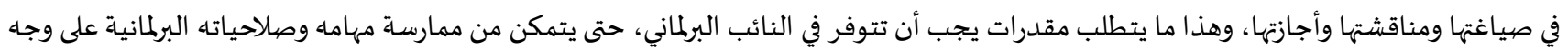

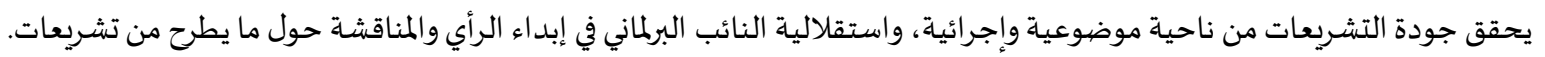

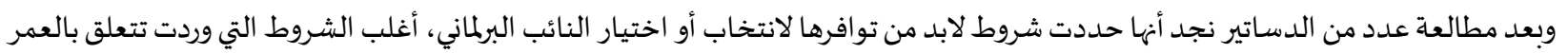

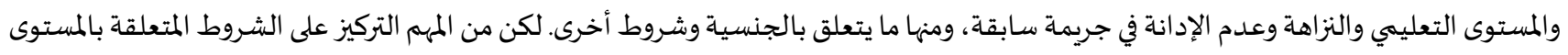

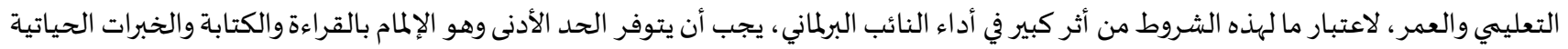

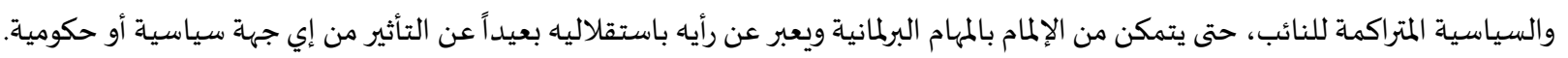

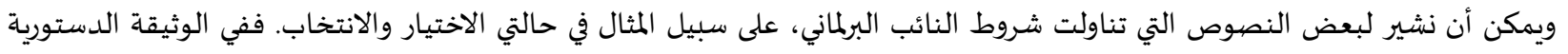

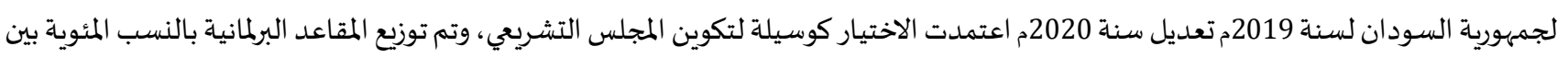

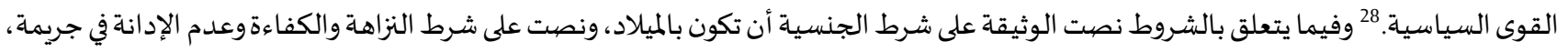

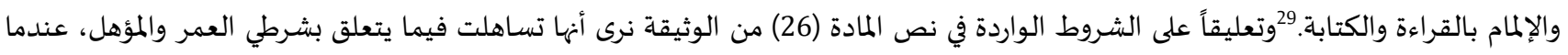

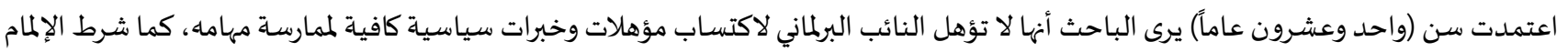

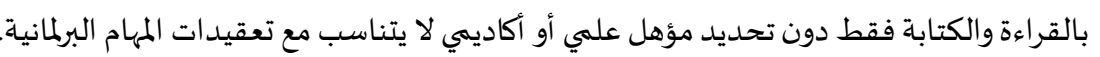

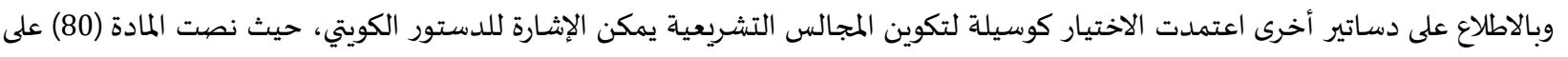

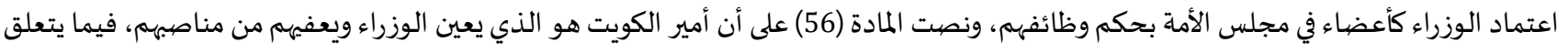

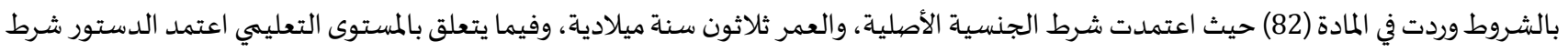

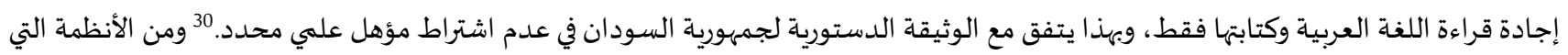

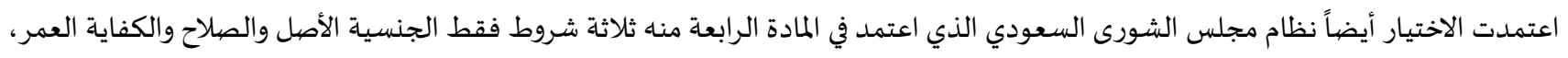
دون تحديد أي مؤهل علمي. مما تقدم يمكن أن نقول طريقة تكوين البرلمان عن طريق التعيين يمكن أن ينتج عنها برلمان يتمتع الأعضياء فياه بكفاءة عالية ومقدرات علمية وخبرات

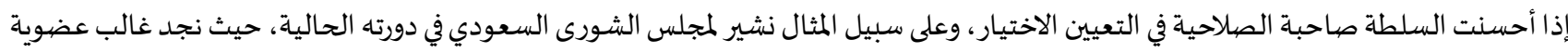

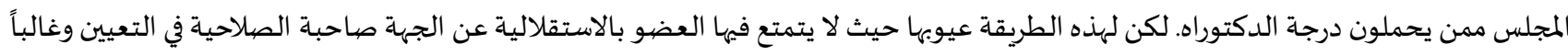

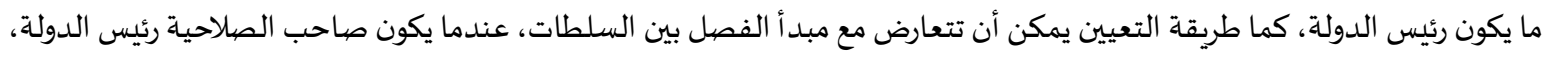

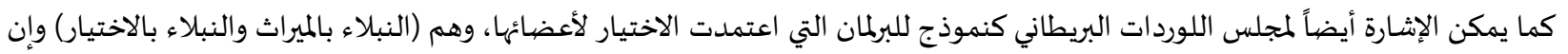

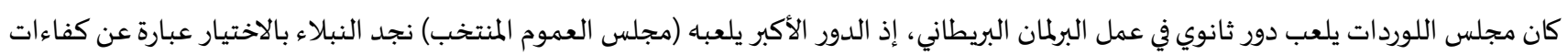

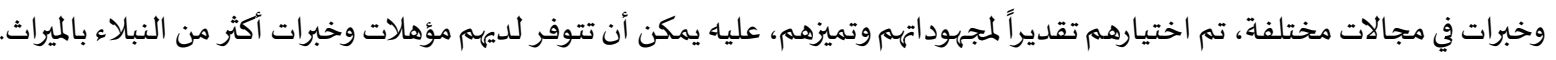

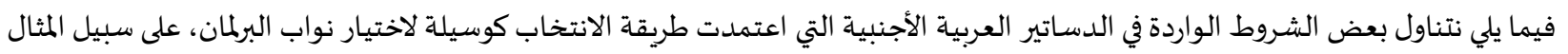

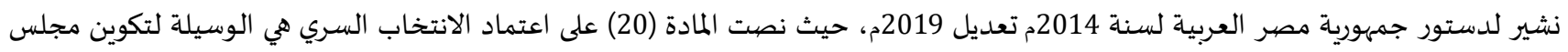

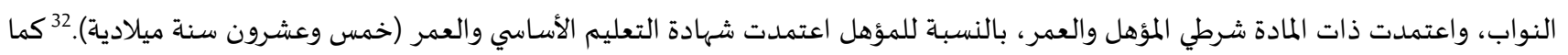

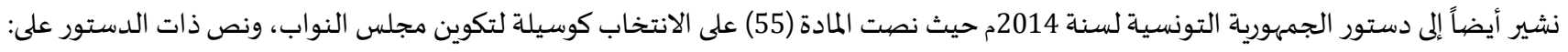

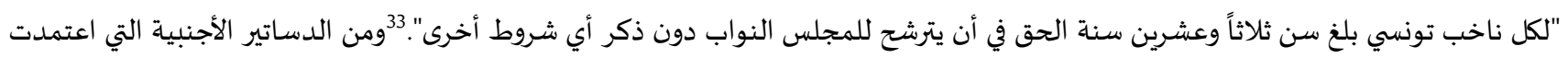

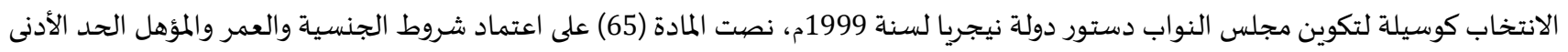

الحصبول على الشهادة المدرسية.

Subject to the provisions of section 66 of this Constitution, a person shall be qualified for election as a member of:

(a) the Senate, if he is a citizen of Nigeria and has attained the age of 35 years; and

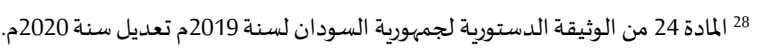

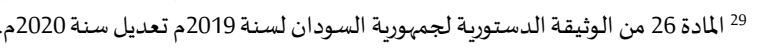

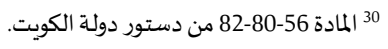
31 المادة الربعة من نظام مجلس الشورى السعودي.

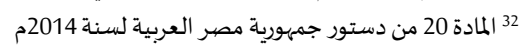

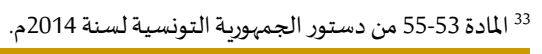


(b) the House of Representatives, if he is a citizen of Nigeria and has attained the age of 30 years;

(2) A person shall be qualified for election under subsection (1) of this section if:

(a) he has been educated up to at least School Certificate level or its equivalent; and

(b) he is a member of a political party and is sponsored by that party.

وخلاصة القول في هذا المطلب يمكن أن نقول اتفقت الدساتير في مسألة وضع شروط للنائب البرلماني، كما اتفقت في كثير من الشروط المتعلقة بالعمر والجنسية الأصلية واختلفت في المؤهل المطلوب منها ما اكتفى بحد الإلمام بالقراءة والكتابة ومنها ما وضع كشرط الحد الأدنى الحصول على شهادة

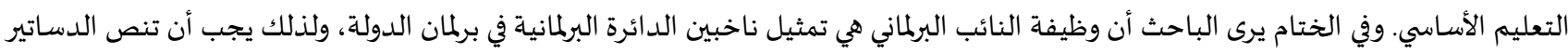

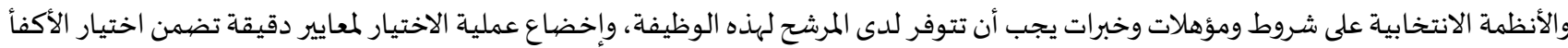

\section{المبحث الثالث: طريقة اختيار النائب البرلماني و أثرها على جودة التشريعات}

جودة التشريعات تكون في الإجراءات التي تحكم عملية سنها في جميع المراحل بداية من مرحلة الاقتراح ونهاية بمرحلة النشر والنفاذ. كما تحدد

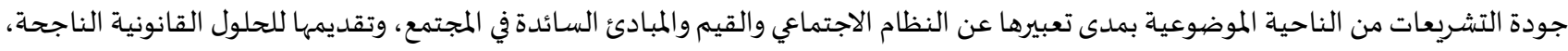

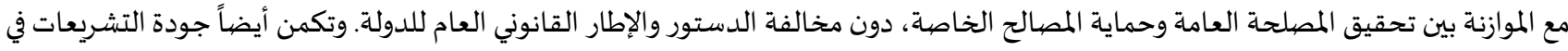
الصياغة التي تحدد بمدى وضوح القواعد التشريعية واتسامها بالشمولية للموضوع والسهولة والوضوح في المفردات والدقة في المعاني والمقاصد.

المطلب الأول: طريقة الاختيار النائب البرلماني و أثرها على الجودة الإجر ائية للتشريعات

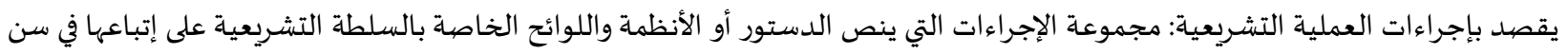

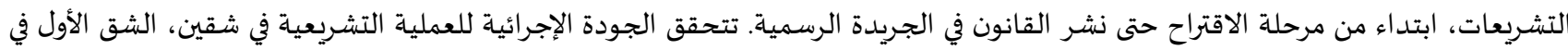

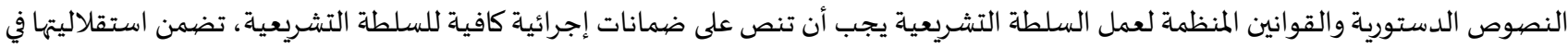

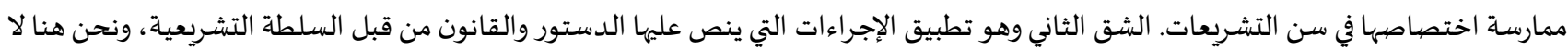

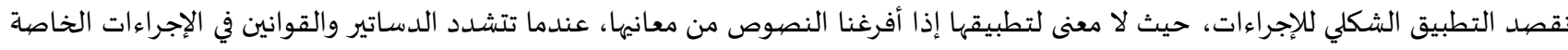

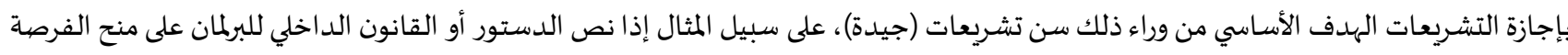

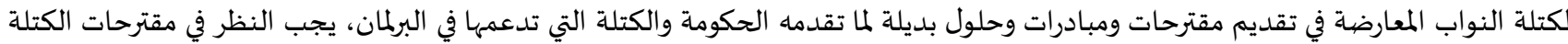

المعارضاة وما تقدماء من بدائل بموضوعية.

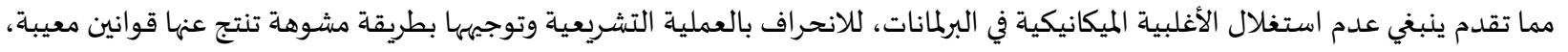

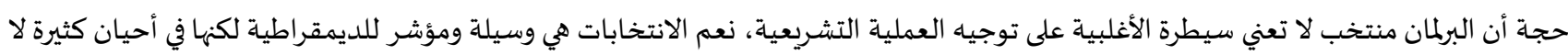

تعني إهدار حقوق الأقلية.

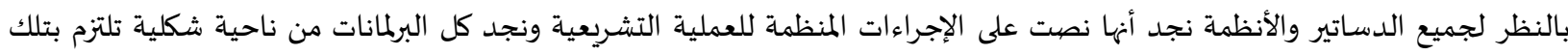

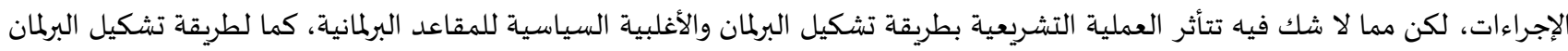

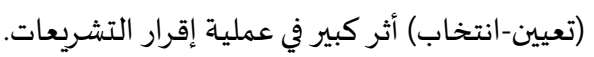

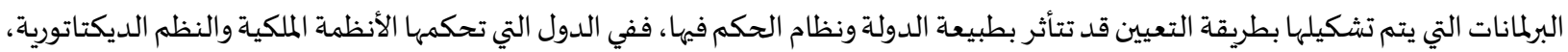
على الرغم من توفر النصوص التي تحكم طريقة تشكيل المجلس التشريعي وحله وشروط العضيوية وتمثيل كافة مكونات الشعب وعزل الأعضاء والنص

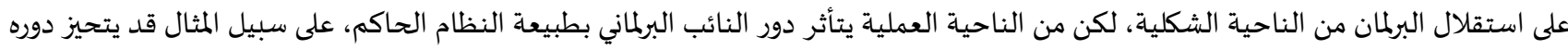

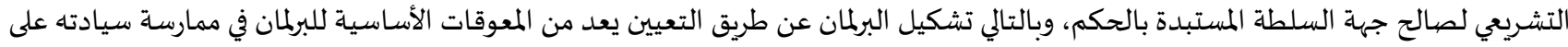

إجازة التشريعات.

ومن المؤكد أيضاً طريقة الانتخابات في تشكيل البرلمانات هي من الوسائل الديمقراطية، كما تعد الضامن لقيام برلمان ذي صففة تمثيلية واسعاة،

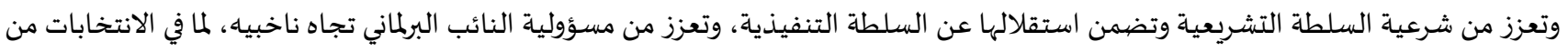

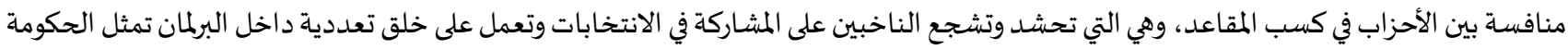

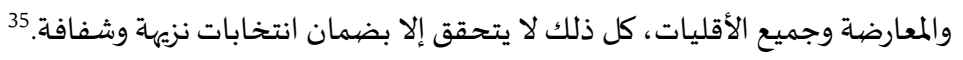

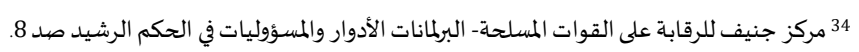

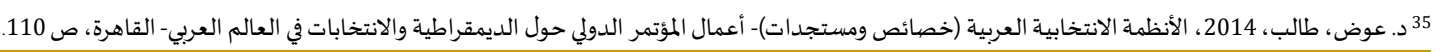


جودة التشريع من الناحية الإجرائية تتأثر بطريقة اختيار النائب في مرحلة مناقشة التشريع وإجازته من قبل البرلمان، وهي من أهم مراحل إصداره التي يظهر فيها دور النائب البرلماني بوضوح، التشريعات الجيدة من الناحية الإجرائية هي التي تتاح فيها الفرصة الكافية للبرلمان في مناقشتها وتمنح فيها

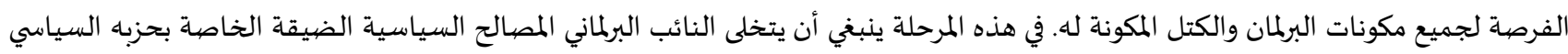

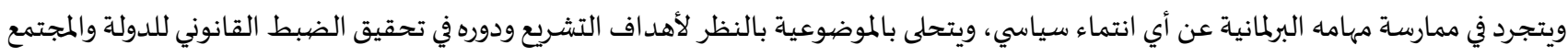
والنظام العام والمصلحة العامة. ويمكن أن نخلص في هذا المطلب إلى أن الضامن الأساسي لجودة العملية التشريعية من الناحية الإجرائية تتمثل في النصوص التي تحكم عمل

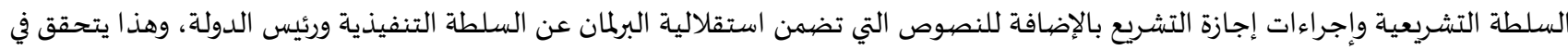
البرلمانات التي يتم تشكيلها بطريقة الانتخابات في تقدير الباحث بذسبة أفضل من البرلمانات التي يتم تشكيلها عن طريقة التعيين.

المطلب الثاني: طريقة الاختيارو أثرها على الجودة الموضوعية للتشريعات

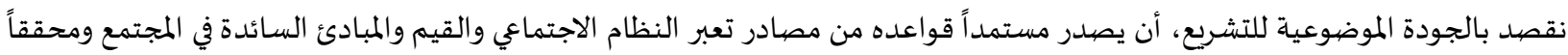

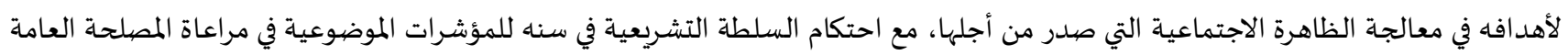

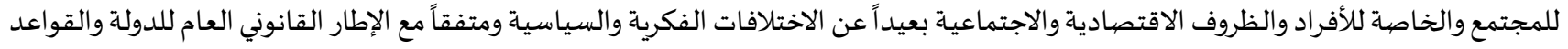
الدستورية. ولما كانت جودة الموضوعية للتشريع تتعلق بالآثار الاجتماعية التي تترتب على معالجة الظاهرة الاجتماعية محل القانون، لذلك كانت مؤشرات جودته

مرتبط بتطبيق التشريع ونفاذه على أرض الواقع وبعد مرور فترة كافية وإجراء دراسات وقياس مدى كفاء كفاءة التشريع في معالجة الظاهرة الاجتماعية. 36

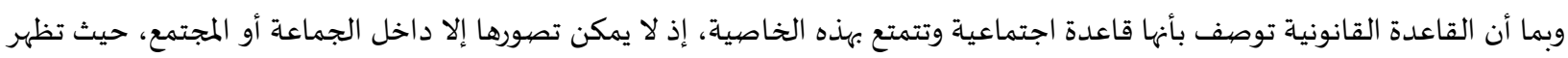

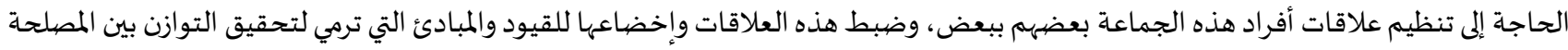

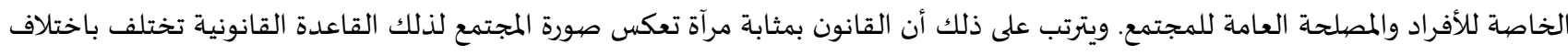

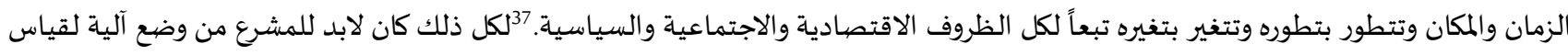

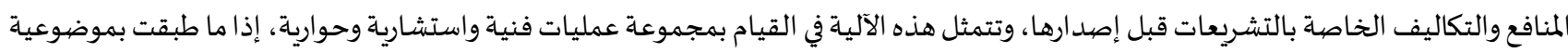

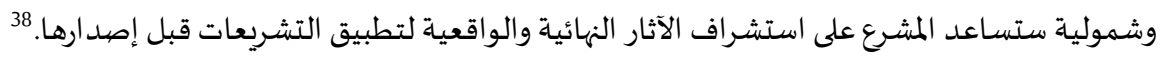

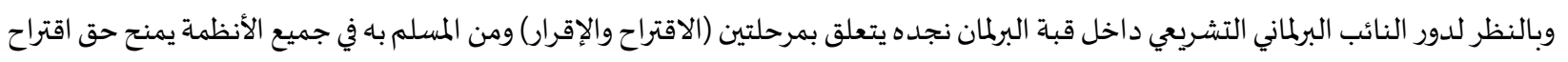

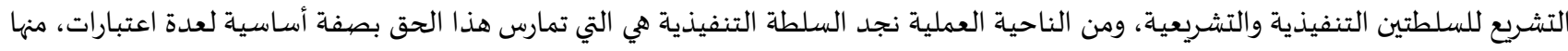

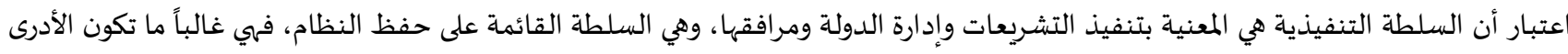

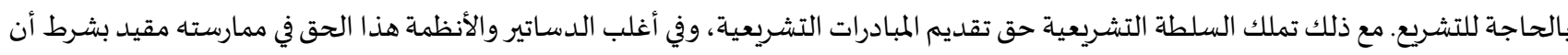
يدفع باقتراح التشريع عدد من النواب، إذ لا يملك نائب برلماني منفرداً الحق في تقديم مقترح لتشريع، هذا فيما يتعلق بمرحلة الاقتراح. أما مرحلة الإقرار

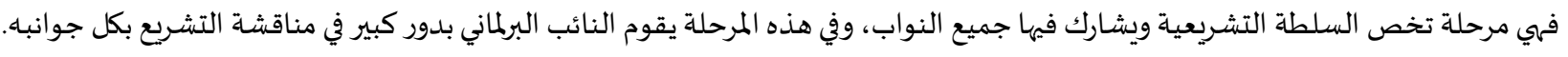

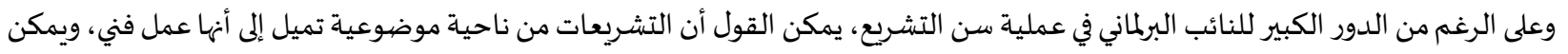

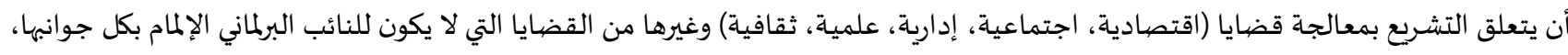

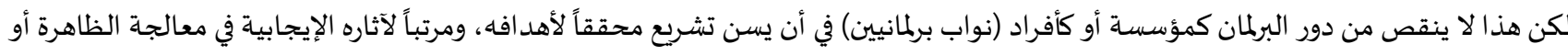

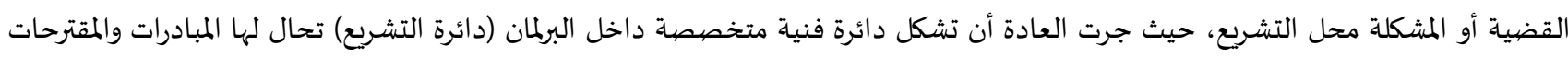

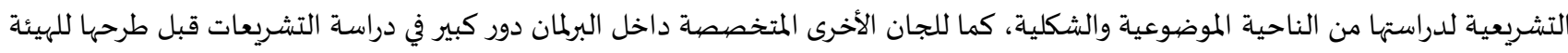

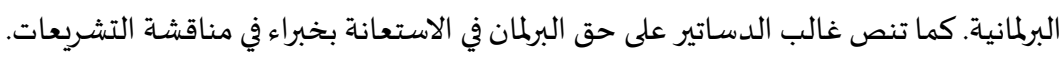

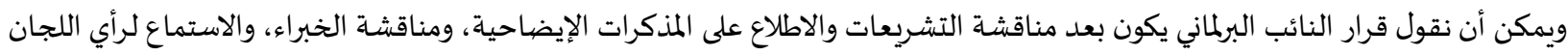
المتخصصة للتشكل لديه الفكرة عن القضية أو الظاهرة أو المشكلة مكان التشريع، وعلى ضوء أنسائل ذلك يتخذ قراره في التصويت بإقرار التشريع أو رفضها.

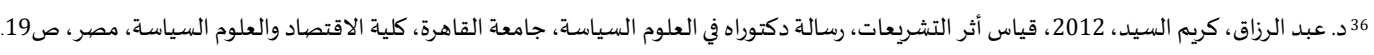

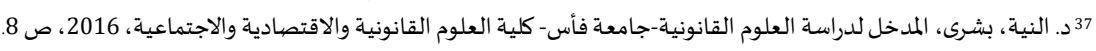

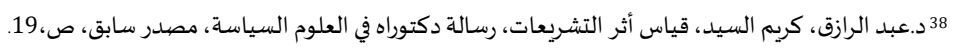


وهنا تظهر أيضاً قدرات النائب البرلماني وخبراته ومؤهلاته التي تمكنه من القيام بدوره وممارسة مهامه المتعلقة بتقديم مقترحات تشريعية أو إقرار

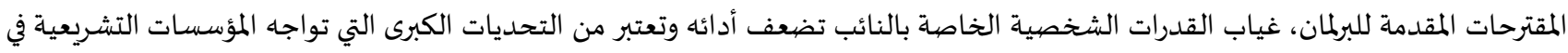
إقرار وصياغة وتصيميم تشريعات فعالة وجيدة. 39

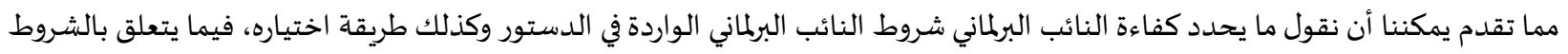

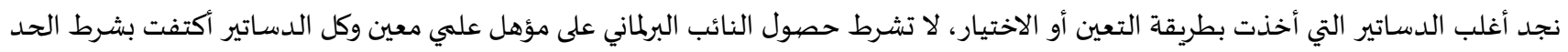

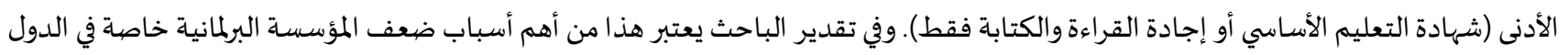

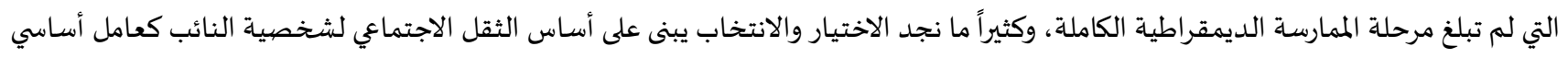

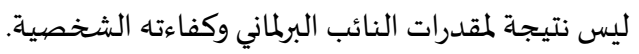
ويمكن أيضاً أن نقول جودة التشريع من الناحية الموضيوعية تتعلق بصورة أساسية باستقلالية النائب وتمائية وتخليه عن كافة القيود السياسية والحزبية

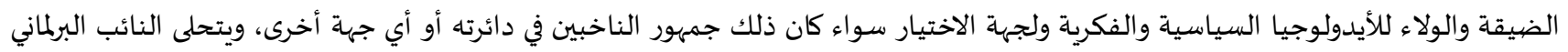

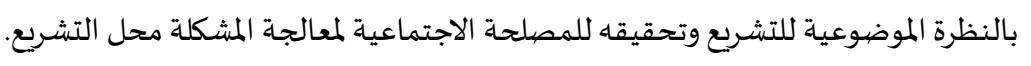

المطلب الثالث: طريقة الاختيارو أثرها على جودة صياغة التشريعات

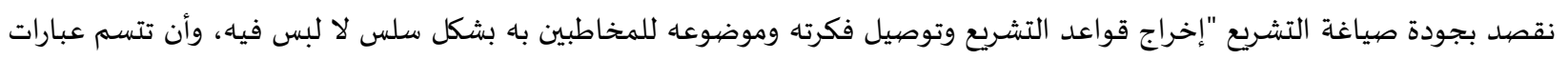
القواعد القانونية فيه بالشمولية للموضوع والسهولة والوضوح في المفردات والدقة في المعاني والمقاصديد"

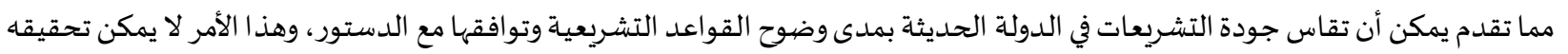

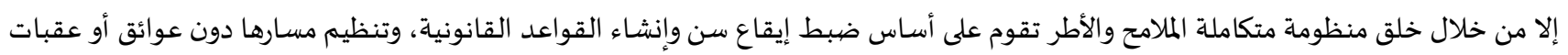
تعطل مسيرتها، أو تنقص من كفاءتها وذلك ضمن سنياسة عامة تشريعية تراعي تحقيق المصلحة العليا للدولة. كما يعد التشريع الجيد أداة لدعم الإدارة

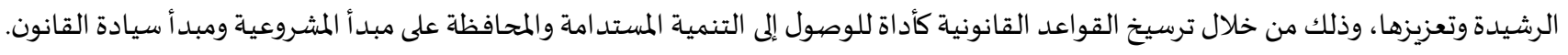

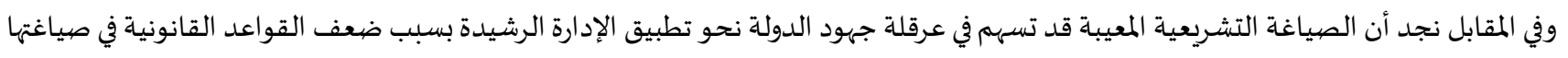
والتعبير عنها بوضيوح ودقة تجعلها منسجمة مع الإطار القانوني العام للدولة والدستور.

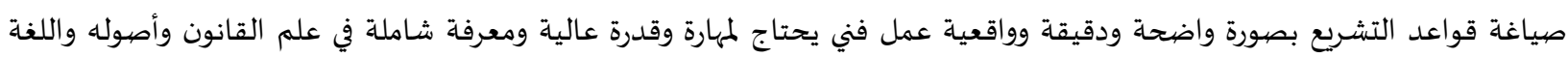
وقواعدها، وأن تكون الجهاة المكلفة ملمة بالقانون وتطوره ومدركة للظروف والزماند واندان والمكان والبيئة، حتى تكون قادرة على بنا الافتراضات القانونية التي ستنعكس حتماً على مشروع القانون المراد إصداره، وذلك باستخد ام عبارات ومفردات تساعد على تطبيق القانون من الناحية العملية وتستوعب وقدان وقائع الحياة من خلال قوالب تشريعية تحقق السياسة العامة للدولة في المجالات السياسية والاقتصادية وادية والاجتماعية المختلفة.

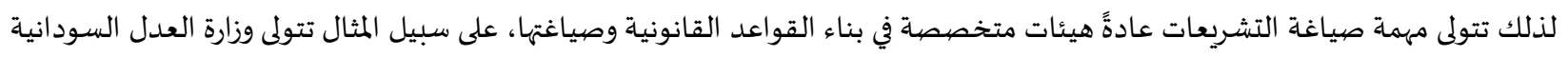

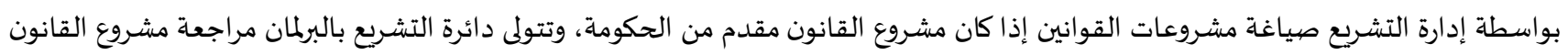
والتدقيق فياه من حيث الصياغة. يجب أن لا يعهد بالصياغة التشريعية إلى جهة واحدة أو مؤسسة واحدة دون غيرها العمل على صياغة مشروع القانون، ويعد من المهم جداً تدقيق المافي

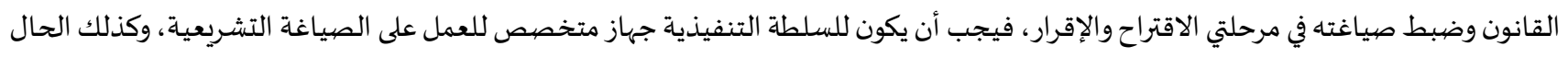

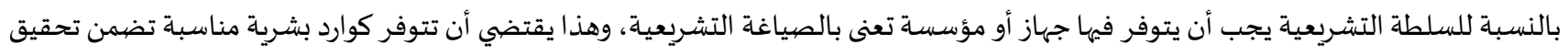

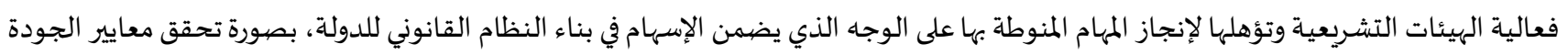

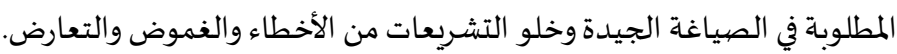

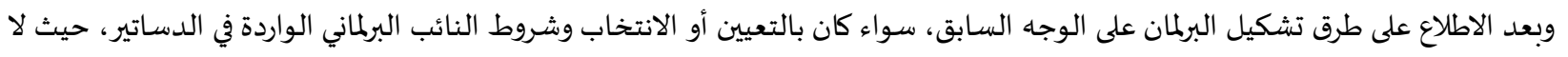

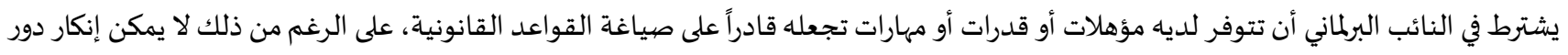

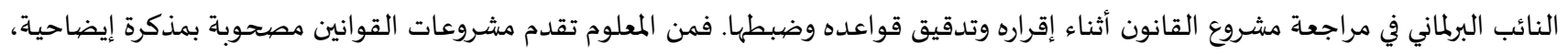
تشتمل على ملخص يبين الأسباب التي دعت لاستحداث القانون وأهداف القانون والغاية المبتغاة منه تأثيره على الأوضاع الاقتصاتيادية والسياسية

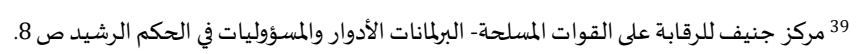

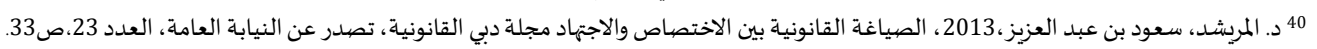

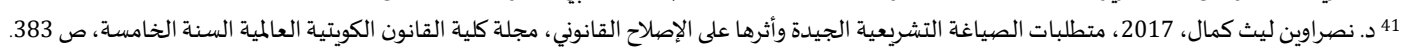

42 
والاجتماعياة، بالإضافة لأبرز السمات العامة للقانون وخصائصيا، بهدف تبسيط فكرة القانون للنواب البرلمانيين، وتعتبر مصدر استرشادي للقانون ينتهي

دورها بإصبد اره.

صياغة التشريع تأخذ بعين الاعتبار مجموعة من العوامل والمعايير المنطقية تتمثل في الظروف التي تحيط بالأفراد وحياتهم الاجتماعية والتقسيم

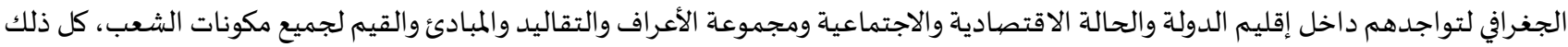

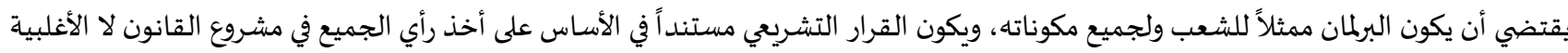

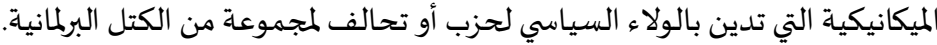

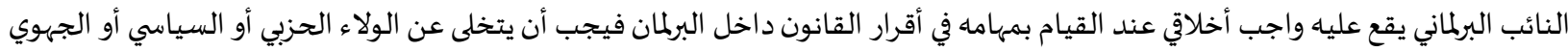

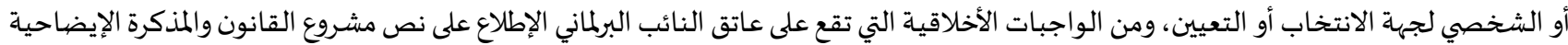

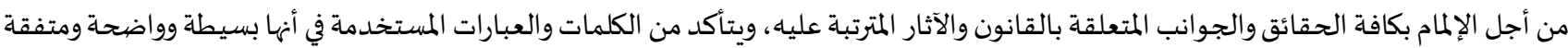
مع قواعد اللغة، ومن الواجب عليه أيضاً أن يتأكد من قواعد مشروع القانون أهها حيادية وعامة ومجردة وخالية من أي غموض ولبس، أو تعارض مع أي أي أبها

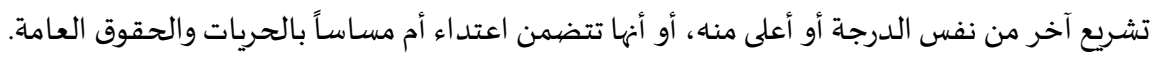
ويمكن أن نقول الأصل أن لا يتأثر النائب البرلماني بجهة تعيينها أو انتخابه في القيام بمهمته في إقرار القانون، وتأكيداً لذلك المبدأ نجد كثير من

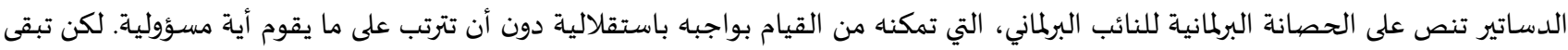

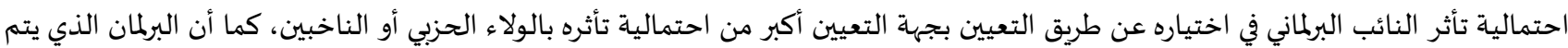

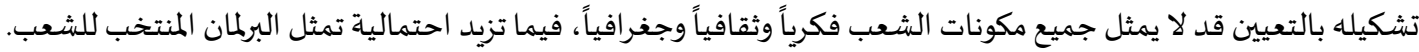

الخاتمةة:

وفي خاتمة هذه الورقة توصل الباحث لمجموعة من النتائج والتوصيات يمكن إجمالها في الآتي: أولاً: النتائج:

تكفل المواثيق الدولية حق المشاركة السياسية للشعوب في إدارة الشؤون العامة، لذلك كفلت دساتير غالب الدول الحق في الانتخاب والترشح لعضوية البرلمان. تشكيل البرلمان كلياً أو جزئياً عن طريق التعيين، يتنافى مع مبدأ الفصل بين السلطات ومبدأ سيادة الشعب، وهذا ما يضعف استقلال وسيادة البربمان في ممارسة سلطته في إقرار التشريعات. استخدام الأغلبية الميكانيكية من القوى السياسية والكتل البرلمانية في أقرار التشريعات، دون النظر في المقترحات والمبادرات التي تقدمها كتلة المعارضة بموضوعياة، قد يضعف من مؤشرات جودة النظام التشريعي للدولة. البرلمان الذي يتشكل عن طريق الانتخاب تكون لله صفة تمثيلية واسعة، ويتمتع فيه النائب بقدر من الاستقلالية في إقرار التشريعات.

ثانياً: التوصيات: على النواب البرلمانيين إدراك جسامة مهمتهم في إقرار التشريع، وأن يتحملوا مسؤوليتهم الأخلاقية في مناقشـة مشروعات القوانين وإقرارها دون تأثير من أية جهاة، حكومية أو سياسية أو فكرية. على النواب البرلمانيين النظر بموضوعية وتجرد لمشروعات القوانين والإطلاع على والمذكرات الإيضاحية المرفقة، والاستعانة بمناقشة الخبرات والجهات المخاطبة بالتشريع. إتاحة الفرصة الكافية للنواب البرلمانيين في مناقشة مشروعات القانون، وتمكين الكتل البرلمانية المعارضية من مناقشة مشروعات القوانين المقدمة من الحكومة وتقديم المشروعات والمقترحات البديلة.

1. إدريس، عبد الله عبد الرحيم إدريس. (2006). إدارة الجودة الشاملة. ط1. منشورات جامعة السودان المفتوحة. الخرطوم. السودان. 2. 3. الأنصاري، ابن منظور جمال الدين محمد بن مكرم.لسان العرب. ج2. الدار المصرية للتأليف والترجما.

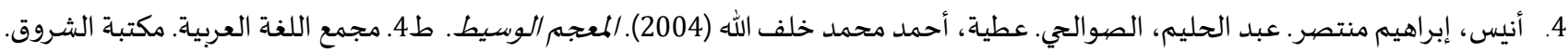

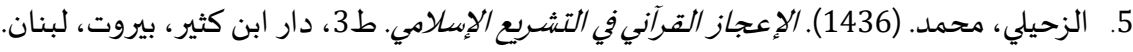


6. الزمخشري، أبي القاسم جار الله محمود بن عمر. (1419-1998). أساس البلاغة. ط1. دار الكتب العلمية. بيروت. لبنان. 7. 8. مركز جنيف للرقابة على القوات المسلحة. ديكاف. البرلمانات الأدوار والمسئوليات في الحكميم الرشيديد.

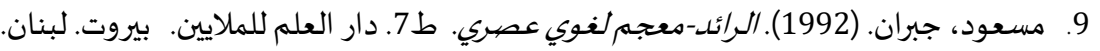

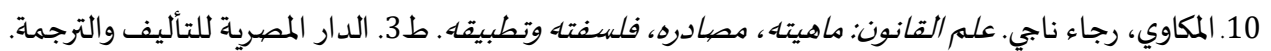
11. النية، بشرى. (2016). المدخل لدراسة العلوم القانونية. جامعة فأس. كلية العلوم القانونية والاقتصادية والاجتماعية.

ثانياً: الرسائل العلمية:

1. جرغون، إيهاب عبد الله (2009).واقع سياسات الاختيار والتعيين في الوظائف الإد/رية. (رسالة علمية لاستكمال متطلبات الماجستير في إدارة الأعمال.

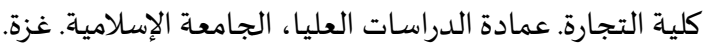

2. عبد الرزاق، كريم السيد.(2012).قياس أثر التشـريعات، رسالة دكتوراه في العلوم السياسـة. جامعة القاهرة. كلية الاقتصاد والعلوم السياسـة، مصر.

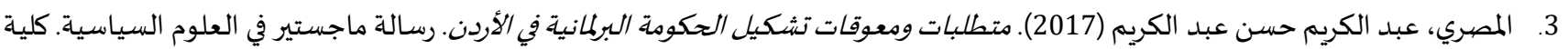

الآداب، جامعة الشرق الأوسط.

ثالثاً: الأبحاث:

1. أويدير، بن سيدي أحمد محند.عبد العزيز، عبادة. (2018). الجودة في التشريع الجزائري والنظريات العلمية ومعايي أيزو 9000-قراءة تحليلية

مقازنة. مجلة التنمية البشرية.

2. 3. عوض، طالب (2014). الأنظمة الانتخابية العربية (خصائص ومستجدات)- أعمال المؤتمر الدولي حول الديمقراطية والانتخابات في العالم العربي. القاهرة.

4. المريشد، سعود بن عبد العزيز (2013). الصياغة القانونية بين الاختصاص والاجتهاد. مجلة دبي القانونية: تصدر عن النيابة العامة، (23). 5. نصراوين، ليث كمال (2017). متطلبات الصياغة التشـريعية الجيدة وأثرها على الإصلاح القانوني. مجلة كلية القانون الكويتية العالمية السنة الخامسة.

6. النية، بشرى (2016). الملدخل لدراسة العلوم القانونية-جامعة فأس- كلية العلوم القانونية والاقتصادية والاجتماعية، ص 8. 
www.refaad.com
المجلة الدولية للدراسـات القانونية والفقهية المقارنة

International Journal of Legal and Comparative Jurisprudence Studies (LCJS)

Journal Homepage: https://www.refaad.com/views/LCJS/Home.aspx

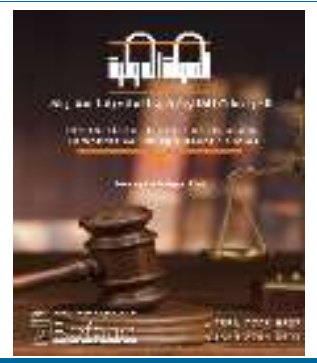

\section{Selection of parliamentarian and its influence on the quality of legislation}

\section{Gamer Eldein Abdarhaman Elsmany Elshikh Brier}

Assistant Professor at College of Sharia and Law, Imam Mahdi University, Republic of Sudan Assistant Professor at College of Administrative Sciences, Department of law, Najran University, KSA gamerdorean@hotmail.com

Received: 4/2/2021 Revised: 14/4/2021 Accepted:3/5/2021 DOI: https://doi.org/10.31559/LCJS2021.2.1.5

Abstract: The current study examined the selection of a parliamentarian and its influence on the quality of legislation. In the beginning, the researcher has to define the main concepts of research (Parliamentarian Quality - Legislation) and then address the process of selecting a parliamentarian and the methods specified by the constitutions of different countries, where most constitutions adopted the method of election, some of them adopted the method of appointment, and others combined appointment and election. In the systems that have adopted the election method, the process of selecting a parliamentarian is affected by a set of factors, including the election system and the integrity of the elections, as well as this method of selection whereby a parliament is formed that is dominated by the political aspect that influences legislation, when political parties exercise their power to influence parliamentarians by using the mechanical majority within the Parliament dome in legislating legislations. In view of electoral systems that have adopted the method of appointment, although the constitutions specify conditions that must be met by a parliamentarian, we do not guarantee the independence of the member of parliament (MP)from the body that has the authority to choose him. Therefore, the main idea of the research revolved around the impact of the process of selecting parliamentarians on the legislative process. In the conclusion, the researcher concluded a set of conclusions, including that the parliament that is formed through elections has a more representative character, and in which the parliamentarian enjoys a degree of independence in approving legislation, and this is only possible with the availability of a set of guarantees included in the research recommendations, the most important of which is the integrity of the elections in addition to provision of procedural guarantees within parliament in approving legislation, including providing parliamentarians with adequate opportunity to discuss draft laws, and enabling opposition parliamentary blocs to discuss draft laws submitted by the government and present draft legislation and alternative proposals.

Keywords: parliamentarian; parliament; Legislation; quality.

\section{References:}

1. Al'tyby, S'd Bn Mtr Almrshdy (1435). Mstlh (Altshry') Wmshtqath Fy Alast'mal Alhqwqy. Mjlt Alaswl Walnwazl: (12).

2. 'wd, Talb (2014). Alanzmh Alantkhabyh Al'rbyh (Khsa's Wmstjdat)- A'mal Alm'tmr Aldwly Hwl Aldymqratyh Walantkhabat Fy Al'alm Al'rby. Alqahrh.

3. Alansary, Abn Mnzwr Jmal Aldyn Mhmd Bn Mkrm. Lsan Al'rb. J2. Aldar Almsryh Lltalyf Waltrjmh.

4. Anys, Ebrahym Mntsr. 'bd Alhlym, Alswalhy. 'tyh, Ahmd Mhmd Khlf Allh (2004). Alm'jm Alwsyt. T4. Mjm' Allghh Al'erbyh. Mktbt Alshrwq.

5. Awydyr, Bn Sydy Ahmd Mhnd.'bd Al'zyz, 'badh. (2018). Aljwdh Fy Altshry' Aljza'ry Walnzryat Al'Imyh Wm'ayyr Ayzw 9000-Qra'h Thlylyh Mqarnh. Mjlt Altnmyh Albshryh. 
6. Edrys, 'bd Allh 'bd Alrhym Edrys. (2006). Edart Aljwdh Alshamlh. T1. Mnshwrat Jam't Alswdan Almftwhh. Alkhrtwm. Alswdan.

7. Esma'yl, Hmad Aljwhry. M'jm Alshah. T2. Dar Al'lm Llmlayyn. Byrwt. Lbnan.

8. Almkawy, Rja' Najy. 'Im Alqanwn: Mahyth, Msadrh, Flsfth Wttbyqh. T3. Aldar Almsryh Lltalyf Waltrjmh.

9. Mrkz Jnyf Llrqabh 'la Alqwat Almslhh. Dykaf. Albrlmanat Aladwar Walms'wlyat Fy Alhkm Alrshyd.

10. Almryshd, S'wd Bn Ebd Al'zyz (2013). Alsyaghh Alqanwnyh Byn Alakhtsas Walajthad. Mjlh Dby Alqanwnyh: Tsdr 'n Alnyabh Al'amh, (23).

11. Ms'wd, Jbran. (1992). Alra'd-M'jm Lghwy 'sry. T7. Dar Al'lm Llmlayyn. Byrwt. Lbnan.

12. Nsrawyn, Lyth Kmal (2017). Mttlbat Alsyaghh Altshry'yh Aljydh Wathrha 'la Aleslah Alqanwny. Mjlt Klyt Alqanwn Alkwytyh Al'almyh Alsnh Alkhamsh.

13. Alnyh, Bshra. (2016). Almdkhl Ldrash Al'lwm Alqanwnyh. Jam't Fas. Klyt Al'lwm Alqanwnyh Walaqtsadyh Walajtma'yh.

14. Alnyh, Bshra (2016). Almdkhl Ldrash Al'lwm Alqanwnyh-Jam't Fas- Klyh Al'lwm Alqanwnyh Walaqtsadyh Walajtma'yh, S 8.

15. Alshymy, Mhmd Ltfy Dkrya. (2009) Alnzam Albrlmany- Albrlman Alanjlyzy Nmwdjaan. Jam't Alqahrh.

16. Alzhyly, Mhmd. (1436). Ale'jaz Alqrany Fy Altshry' Aleslamy. T3, Dar Abn Kthyr, Byrwt, Lbnan.

17. Alzmkhshry, Aby Alqasm Jar Allh Mhmwd Bn 'mr. (1419-1998). Asas Alblaghh. T1. Dar Alktb Al'lmyh. Byrwt. Lbnan. 